\title{
Investigation of biomass components on the slow pyrolysis products yield using Aspen Plus for techno-economic analysis
}

\author{
Muhammad Shahbaz $^{1} \cdot$ Ahmed AlNouss $^{1} \cdot$ Prakash Parthasarathy $^{1} \cdot$ Ali H. Abdelaal ${ }^{1} \cdot$ Hamish Mackey $^{1}$. \\ Gordon McKay ${ }^{1} \cdot$ Tareq Al-Ansari $^{1,2}$ (B)
}

Received: 9 July 2020 / Revised: 21 September 2020 / Accepted: 25 September 2020 / Published online: 10 October 2020

(C) The Author(s) 2020

\begin{abstract}
Prior information on the pyrolysis product behaviour of biomass components-cellulose, hemicellulose and lignin is critical in the selection of feedstock as components have a significant influence on the pyrolysis products yield. In this study, the effect of biomass components on the yield of slow pyrolysis products (char, bio-oil and syngas) is investigated using a validated ASPEN Plus ${ }^{\circledR}$ model. The model is simulated at a temperature of $450^{\circ} \mathrm{C}$, a heating rate of $10^{\circ} \mathrm{C} / \mathrm{min}$ and a solid residence time of $30 \mathrm{~min}$. The results indicated that at the given conditions, lignin contributed 2.4 and 2.5 times more char yield than cellulose and hemicellulose. The hemicellulose contributed 1.33 times more syngas yield than lignin while the cellulose and hemicellulose contributed 8.67 times more bio-oil yield than lignin. Moreover, the cost involved in the production of char using lignin (110 $\$ /$ ton $)$ is significantly economical than using cellulose ( $285 \$$ /ton $)$ and hemicellulose ( 296 /ton). The net $\mathrm{CO}_{2}$ emission of lignin pyrolysis is 4.14 times lower than cellulose pyrolysis and 3.94 times lower than hemicellulose pyrolysis. It can be concluded that lignin pyrolysis is more advantageous than cellulose and hemicellulose pyrolysis. In the selection of feedstock for the slow pyrolysis, the feedstock with more lignin content is preferred.
\end{abstract}

Keywords Cellulose $\cdot$ Hemicellulose $\cdot$ Lignin $\cdot$ Slow pyrolysis $\cdot$ Aspen Plus ${ }^{\circledR} \cdot$ Techno-economic analysis

\section{Introduction}

Modern society is primarily driven by fossil fuels which contribute towards resource depletion and pollution [1]. The changes in climate, limited and unequal distribution of fossil fuel sources and imbalanced energy trade have increased the importance of alternative sources of energy such as biomass $[2,3]$. There is a global impetus to identify low carbon and sustainable sources of energy as agreed by most signatories to the Paris Climate agreement in 2015, for which

Gordon McKay

gmckay@hbku.edu.qa

Tareq Al-Ansari

talansari@hbku.edu.qa

1 Division of Sustainable Development, College of Science and Engineering, Hamad Bin Khalifa University, Education City, Doha, Qatar

2 Division of Engineering Management and Decision Sciences, College of Science and Engineering, Hamad Bin Khalifa University, Education City, Doha, Qatar the International Panel on Climate Change (IPCC) proposed that bio-energy would be a suitable alternative $[4,5]$. Lignocellulosic biomass exists in large quantities as nonedible biomass, mainly composed of forestry and agricultural wastes. It primarily consists of carbohydrate polymers, specifically cellulose (C6-sugars) and hemicellulose (mostly C5sugars) and lignin [6]. It also contains low amounts of proteins, lipids, nitrogenous compounds, non-structural carbohydrates, waxes, chlorophyll and mineral matter [7]. Cellulose is a linear polymer based on glucose. Hemicellulose is a type of heterogeneous polysaccharide, which contain C6 and C5 sugars. Lignin, on the other hand, is composed of three-dimensional, complex phenylpropane compounds [8]. In addition to these three components, lignocellulosic biomass contains $5-15 \%$ of proteins and a small proportion of extractives. The composition of cellulose, hemicellulose and lignin varies from biomass to biomass and is typically in the range of 30 $50 \%$ (cellulose), 20-40\% (hemicellulose) and 10-30\% (lignin) respectively [7].

Biomass can be converted into fuels/chemicals by biological and thermochemical conversion processes and it is the only source that can produce solid, liquid and gaseous fuels 
$[9,10]$. Amongst the thermochemical conversion processes, pyrolysis is primarily employed for the generation of liquid (bio-oil), gas (syngas) and solid (char) fuels [11, 12]. Pyrolysis is the process of thermal decomposition of organic materials to obtain a set of solid, liquid and gaseous products in the absence of oxygen [13, 14].

Cellulose is a long-chain polysaccharide that exhibits crystalline and amorphous regions. The arrangement of molecules in the crystalline region is uniform and ordered, while in the amorphous region, the arrangement is loose and disordered. The crystalline region of cellulose shows better thermal stability than the amorphous region due to its packed cellulose structure $[15,16]$. When cellulose material is subjected to heat during the pyrolysis process, the amorphous region degrades first followed by the crystalline region [17]. On the other hand, hemicellulose is constituted of amorphous structured shortchain heteropolysaccharides such as pentoses, xylose and arabinose. During pyrolysis, the behaviour of hemicellulose is based on those attributes of these building blocks, which turn into a foamy material at higher temperatures resulting in an increase in the char volume [18]. While lignin is made up of aromatic matrices which imparts the strength and rigidity to the plant cell walls. For this reason, the thermal stability of lignin is considerably higher than hemicellulose and cellulose [18]. The decomposition behaviour of biomass pseudocomponents was individually investigated by Yang et al. [19]. The decomposition temperature range was observed to be $220-315^{\circ} \mathrm{C}, 314-400{ }^{\circ} \mathrm{C}$ and $160-900{ }^{\circ} \mathrm{C}$ for hemicellulose, cellulose and lignin respectively [19]. Among the three components, hemicellulose and cellulose undergo decomposition easily. However, the decomposition of lignin is a complex phenomenon which can be evidenced by its long decomposition temperature range [20]. When pyrolysed, all these biomass components produce the same gaseous components $\left(\mathrm{CO}, \mathrm{CO}_{2}, \mathrm{CH}_{4}\right.$ and other hydrocarbons) but with a varying composition, which depends upon the nature of the biomass components and pyrolysis operating parameters. However, a further investigation demonstrated that hemicellulose favours $\mathrm{CO}_{2}$ yield; cellulose supports $\mathrm{CO}$ yield, while lignin encourages $\mathrm{H}_{2}$ and $\mathrm{CH}_{4}$ yield. The discrepancy in the behaviour of these components is attributed to the inherent physical and chemical characteristics of these components [21]. Upon pyrolysis, these biomass components apart from generating char, bio-oil and syngas $\left(\mathrm{CO}, \mathrm{CO}_{2}, \mathrm{CH}_{4}, \mathrm{H}_{2}\right)$ also generate a wider range of products. A few major products of these components and their commercial uses are presented in Table 1.

The pyrolysis of biomass involves a number of complex physical and chemical processing steps to generate a number of products and intermediates [24]. In addition, the pyrolysis process is highly sensitive to thermodynamic properties, operating conditions dependent properties, time-dependent properties and material properties. Hence, modelling and simulation is the best approach to study the pyrolysis process in order to understand the thermochemical reaction mechanism and optimization process. The modelling and simulation studies save both time and cost involved in practical experimentations [25]. Aspen Plus is an advanced system-oriented software for process engineering that enables the modelling of biological, chemical and physical systems [26]. Peters et al. [27]
Table 1 Biomass components and their major products upon pyrolysis [22, 23]

\begin{tabular}{|c|c|c|}
\hline Components & Products & Applications \\
\hline \multirow[t]{5}{*}{ Cellulose } & Levoglucosan & $\begin{array}{l}\text { Often used as a chemical tracer for investigating biomass } \\
\text { combustion in atmospheric chemistry studies. }\end{array}$ \\
\hline & 5-HMF & Used as a biomarker and flavouring agent in the food industry. \\
\hline & Furfural & $\begin{array}{l}\text { Used in the synthesis of solvents (Tetrahydrofurfuryl alcohol } \\
\text { (THFA)), polymers (Furan resins), fuels and other useful } \\
\text { chemicals (Furfuryl alcohol). }\end{array}$ \\
\hline & Methyl glyoxal & Used as a medicine in the treatment of cancer. \\
\hline & Hydroxyacetaldehyde & Used in the synthesis of Glyceraldehyde. \\
\hline \multirow[t]{5}{*}{ Hemicellulose } & Phenols & Used as a precursor to synthesize plastics. \\
\hline & Cyclic ketone & Used in the production of Nylon (Cyclohexanone). \\
\hline & Hydroxyacetone & Used as a flavouring agent in the food industry. \\
\hline & Propanoic & Used in the synthesis of polymers. \\
\hline & Acetic acid & $\begin{array}{l}\text { Used primarily in the production of cellulose acetate, polyvinyl } \\
\text { acetate, synthetic fibres, and fabrics. }\end{array}$ \\
\hline \multirow[t]{3}{*}{ Lignin } & Benzenediols & Used in the synthesis of pesticides, pharmaceuticals and perfumes. \\
\hline & Catechol (phenol) & $\begin{array}{l}\text { Used as a precursor to synthesize pesticides, flavours, and } \\
\text { fragrances. }\end{array}$ \\
\hline & Methoxyphenol & $\begin{array}{l}\text { Used as an intermediate in the synthesis of antioxidants, } \\
\text { pharmaceuticals, plasticizers, and dyestuffs. }\end{array}$ \\
\hline
\end{tabular}


Table 2 The properties of the individual pseudo-biomass components

\begin{tabular}{llll}
\hline Analysis & Cellulose & Hemicellulose & Lignin \\
\hline Proximate analysis (wt.\%) (dry basis) & & \\
Moisture & 3.00 & 3.00 & 3.00 \\
Fixed carbon & 5.75 & 16.85 & 32.47 \\
Volatile matter & 94.25 & 83.15 & 64.66 \\
Ash & 0.00 & 0.00 & 2.87 \\
Total & 100.00 & 100.00 & 100.00 \\
Ultimate analysis (wt.\%) (dry basis) & & \\
C & 41.46 & 40.69 & 5.27 \\
H & 5.97 & 5.75 & 1.10 \\
$\mathrm{~N}$ & 0.07 & 0.04 & 33.52 \\
O & 52.48 & 53.49 & 2.87 \\
S & 0.02 & 0.03 & 0.00 \\
Cl & 0.00 & 0.00 & 0.25 \\
Ash & 0.00 & 0.00 & 56.99 \\
Total & 100.00 & 100.00 & 100.00 \\
Heating value $(\mathrm{MJ} / \mathrm{kg})$ & & \\
LHV & 15.36 & 14.57 & 24.55 \\
Reference & Ma et al. [18] & Ma et al. [18] & Ma et al. [18] \\
\hline
\end{tabular}

developed a pyrolysis process using a novel kinetic reaction model based on the lignin, cellulose and hemicellulose in Aspen Plus. The model used a beechwood feedstock with a set of 149 reactions representing volatilisation, decomposition and re-composition steps. The secondary pyrolysis reactions were represented using linear regression to account for the slow and intermediate pyrolysis reactions. The developed kinetic model in Aspen Plus predicted a higher product yield for lignin-rich biomass compared to cellulosic and hemicellulosic biomass.

In another study, Peters et al. [28] used a kinetic reaction mechanism in Aspen Plus to study the effect of feedstock composition (alkali mental, ash, lignin, cellulose and hemicellulose), residence time and temperature on the pyrolysis product yields and composition. A comprehensive model was used to predict the production of bio-oil. The results showed a good agreement with the literature values for a thermodynamic equilibrium model simulated in Aspen Plus to study the lignocellulosic biomass pyrolysis process [29]. The developed model was used to predict the performance of the pyrolysis process considering the process parameters. The results were in good agreement with literature values [29]. Xianjun et al. [30] employed a yield-based reaction model using Aspen Plus to investigate biomass pyrolysis. A compiled FORTRAN subroutine embedded in the yield reactor was used to estimate the yields of the pyrolysis products. The study investigated the effect of temperature on the pyrolysis product yields and composition. The results indicated an increase in the yield of noncondensable gases and a decrease in the yield of char and bio- oil with an increase in temperature. In addition, the model indicated the utilisation of Aspen Plus to simulate biomass pyrolysis process by showing high agreement with literature experimental values. The life cycle performance of lignocellulosic energy crops was investigated by simulating a slow pyrolysis process in Aspen Plus [31]. The pyrolysis process generating biochar and heat was compared with direct biomass combustion. The model was used to investigate the effect of biochar on biomass yield and the long-term stability of biochar in the soil. In addition, biochar producing systems demonstrated a significant potential for carbon reduction.

The study on the behaviour of individual biomass components during pyrolysis will not only help in the prediction of slow pyrolysis products yield but also help in the selection of the feedstock. Simulation studies investigating the effect of individual biomass components on the yield of pyrolysis products are limited. Furthermore, the studies on the technoeconomic analysis of the slow pyrolysis of individual biomass pseudo-components are also limited. Hence, in this study, the influence of cellulose, hemicellulose and lignin on the yield of char, bio-oil and syngas is investigated using a validated ASPEN Plus model. A detailed techno-economic analysis on the slow pyrolysis of cellulose, hemicellulose and lignin is also carried out using the developed model.

The objective of the study is to investigate the effect of biomass components on the product yields (char, bio-oil and syngas) of slow pyrolysis. The novelty of the work lies in its techno-economic analysis of slow pyrolysis of individual biomass components. The results of the techno-economic analyses of slow pyrolysis of cellulose, hemicellulose and lignin are compared with one another and the best biomass component is identified. The prediction on the yield of slow pyrolysis products will largely be helpful in the selection of the appropriate feedstock for the slow pyrolysis, whereas the cost analysis will be helpful in assessing the optimum economics of the pyrolysis process. In spite of its advantages, the current simulation study has a drawback. The study is based on the assumption that there is no interaction between individual components. However, in a real scenario, i.e. during the pyrolysis of natural biomass, there will definitely be some interactions between the components. Hence, based on this assumption, a slight difference in the slow pyrolysis products yield between the actual experimental results and predicted results is expected.

\section{Materials and methods}

\subsection{Model development basis and assumptions}

In this study, Aspen Plus ${ }^{\circledR}$ V9 was selected for the development of a process because the aims of this study are to use advanced simulation techniques to investigate the effect of pseudo-biomass components on the yield of the slow 
Fig. 1 Process flowsheet of the pyrolysis system simulated in Aspen Plus

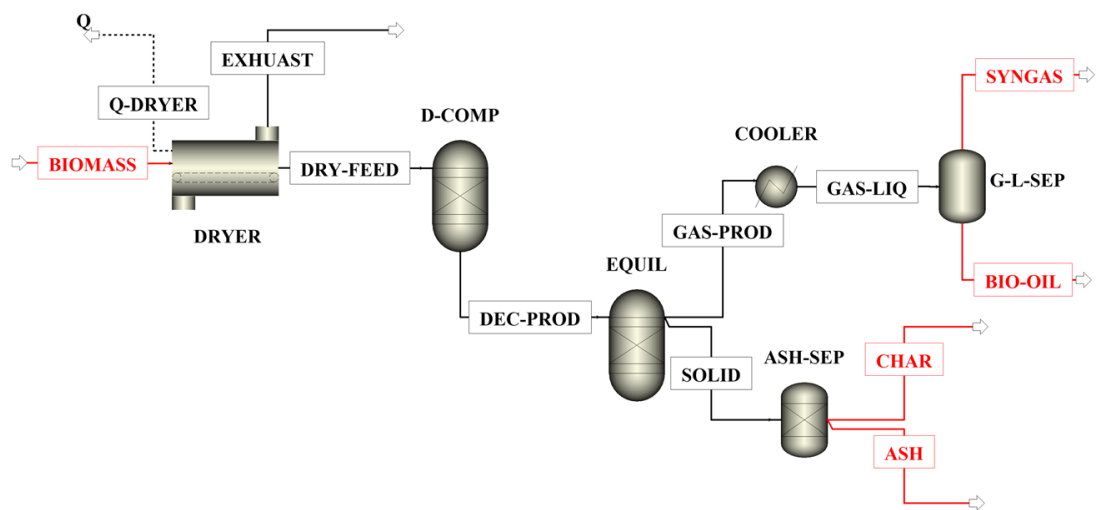

The model is simulated on the basis of zerodimensional blocks, neglecting tar formation, neglecting pressure drops (isobaric operation), neglecting heat losses and assuming a uniform temperature distribution. The zero-dimensional blocks provide the basis of a model system's thermodynamic property. These simulation blocks are assumed to be fully insulated and operating at atmospheric pressure with reaction temperature equals to exit stream temperature. The rest of assumptions are implemented to reduce the complications on the simulated models and support the kinetic-free equilibrium basis.

\subsection{Flowsheet and process}

The process flowsheet of the Aspen Plus model is presented in Fig. 1. It commences with a dryer block operating at $150{ }^{\circ} \mathrm{C}$ primarily to remove any extra moisture content present in the lignocellulosic biomass feedstock. The block reduced the water amount present in the feedstock by specifying the exit stream moisture content. The dried stream entered the decomposition block simulated as a yield reactor in which biomass was converted into conventional components on the basis of the ultimate analysis of biomass using a calculator formulation unit $[32,33]$. The streams from the yield reactor were taken to another reactor where chemical composition and phase equilibrium were calculated by minimizing Gibb's free energy at the specified temperature and pressure. The reactor also acted as a twophase separator, where the gases were separated leaving the top of the reactor and directed to the cooler and the solids (comprises of char and ash) were separated at the base of the reactor. The cooler reduced the temperature and produced a vapour/liquid mixture, which was separated into syngas and bio-oil. Whereas, the solid stream was sent to a solid separator where char was separated from ash fraction.

In order to simulate the real and non-polar species presented in the model, the Peng-Robinson equation of state with 
Table 4 Economic parameters and relations used by Aspen Plus software

\begin{tabular}{|c|c|c|c|}
\hline Economic analysis & \multicolumn{2}{|l|}{ Relation } & Equation number \\
\hline Investment cost & \multicolumn{2}{|c|}{$\begin{array}{l}\text { (Equipment cost }+ \text { equipment installation cost }+ \text { civil, mechanical, electrical and } \\
\text { instrumentation cost }+ \text { administration cost }+ \text { contingencies })\end{array}$} & (1) \\
\hline Operation cost & \multicolumn{2}{|c|}{$\begin{array}{l}\text { Operating and labour charges }+ \text { maintenance cost }+ \text { plant overhead cost }+ \text { administration } \\
\text { cost }\end{array}$} & (2) \\
\hline Annualised cost & \multicolumn{2}{|c|}{ Invesment Cost $\frac{\mathrm{i}(1+\mathrm{i})^{\mathrm{n}}}{(1+\mathrm{i})^{n}-1}+$ operation cost + raw material cost } & (3) \\
\hline Operating charges & \multicolumn{2}{|c|}{$25 \%$ of the shift operating labour cost /period } & (4) \\
\hline Plant overhead & \multicolumn{2}{|c|}{$50 \%$ of labour and maintenance cost/period } & (5) \\
\hline Working capital & \multicolumn{2}{|c|}{$5 \%$ of investment cost/period } & (6) \\
\hline Administration cost & \multicolumn{2}{|c|}{$8 \%$ of total operation costs (operating charges) } & (7) \\
\hline Salvage value & \multicolumn{2}{|c|}{$20 \%$ of project capital cost } & (8) \\
\hline Environmental emissions & \multicolumn{2}{|c|}{ Relation } & Equation number \\
\hline Net stream $\mathrm{CO} 2$ equivalents $\left[\mathrm{CO}_{2}-\mathrm{e}\right]$ & \multicolumn{2}{|c|}{ (Product streams - feed streams) x GWP } & (9) \\
\hline Economic parameters & Values & Economic parameters & Values \\
\hline No. of years (n) & 20 & Weeks per year & 52 \\
\hline Hours per year & 8766 & Length of start-up & 20 weeks \\
\hline $\begin{array}{l}\text { Duration of engineering, procurement } \\
\text { and commissioning (EPC) }\end{array}$ & 33 weeks & Duration of construction phase & 20 weeks \\
\hline Depreciation & Straight line & Interest rate (i) & $20 \% /$ year \\
\hline Unit cost for supervisor & $35 / \mathrm{h}$ & Supervisors per shift & 1 \\
\hline Unit cost for the operator & $20 / \mathrm{h}$ & Operators per shift & 3 \\
\hline Raw material cost & $\$ 60 /$ ton & Syngas price $[37]$ & $\$ 0.11 / \mathrm{m}^{3}$ \\
\hline Bio-oil price [38] & $\$ 0.16 / 1$ & Biochar price [39] & $\$ 0.2 / \mathrm{kg}$ \\
\hline
\end{tabular}

Boston-Mathias modifications was selected. The model was used to simulate the three pseudo-biomass components: lignin, cellulose and hemicellulose. The operating conditions of the pyrolysis model are presented in Table 3 for the three single component simulation models used to estimate the

Table 5 The input data and results of the literature and the developed model

\begin{tabular}{lll}
\hline & Present model & Visconti et al. [29] \\
\hline Model conditions & & \\
Feedstock input $(\mathrm{kg} / \mathrm{h})$ & 50 & 50 \\
Feed T $\left({ }^{\circ} \mathrm{C}\right)$ & 25 & 25 \\
Feed P $($ bar $)$ & 1 & 1 \\
Drying T $\left({ }^{\circ} \mathrm{C}\right)$ & 500 & 500 \\
Max outlet drying moist $(\%)$ & 7.86 & 7.86 \\
Pyrolysis T $\left({ }^{\circ} \mathrm{C}\right)$ & 500 & 500 \\
Cooling T $\left({ }^{\circ} \mathrm{C}\right)$ & 40 & 40 \\
Results & & \\
Syngas composition $($ mol. \%) & & \\
$\mathrm{H}_{2}$ & 41.2 & 41.0 \\
$\mathrm{CO}$ & 4.6 & 5.0 \\
$\mathrm{CO}_{2}$ & 25.8 & 26.0 \\
$\mathrm{CH}_{4}$ & 17.1 & 17.0 \\
$\mathrm{H}_{2} \mathrm{O}$ & 11.1 & 11.0 \\
\hline
\end{tabular}

characteristics of the pyrolysis process. These operating conditions are selected on the basis of literature study by Kabir et al. [26]. The focus of this study is to analyse the production rates of char, syngas and bio-oil, product yields, moisture and ash effluents and most importantly the economic and environmental performance.

\subsection{Techno-economic evaluation}

The techno-economic-environmental analysis was conducted by means of the built-in tools of Aspen Plus.

Table 6 The results of the pyrolysis simulation model

\begin{tabular}{llll}
\hline Output results & Cellulose & Hemicellulose & Lignin \\
\hline Char $(\mathrm{kg} / \mathrm{h})$ & $22,956.10$ & $22,111.51$ & 2636.97 \\
Syngas $(\mathrm{kg} / \mathrm{h})$ & $50,871.16$ & $52,056.49$ & $38,931.22$ \\
Syngas $\left(\mathrm{Nm}{ }^{3} / \mathrm{h}\right)$ & 108.44 & 107.65 & 85.67 \\
Bio-oil $(\mathrm{kg} / \mathrm{h})$ & $26,172.74$ & $25,832.00$ & 3151.51 \\
Bio-oil $(\mathrm{L} / \mathrm{h})$ & $26,224.01$ & $25,882.41$ & 3159.48 \\
Moisture $(\mathrm{kg} / \mathrm{h})$ & 0.00 & 0.00 & 0.00 \\
Ash $(\mathrm{kg} / \mathrm{h})$ & 0.00 & 0.00 & $55,280.30$ \\
Products yield $(\%)$ & & & \\
Char & 23 & 22 & 58 \\
Syngas & 51 & 52 & 39 \\
Bio-oil & 26 & 26 & 3 \\
\hline
\end{tabular}


Fig. 2 Effect of cellulose on the slow pyrolysis products yield

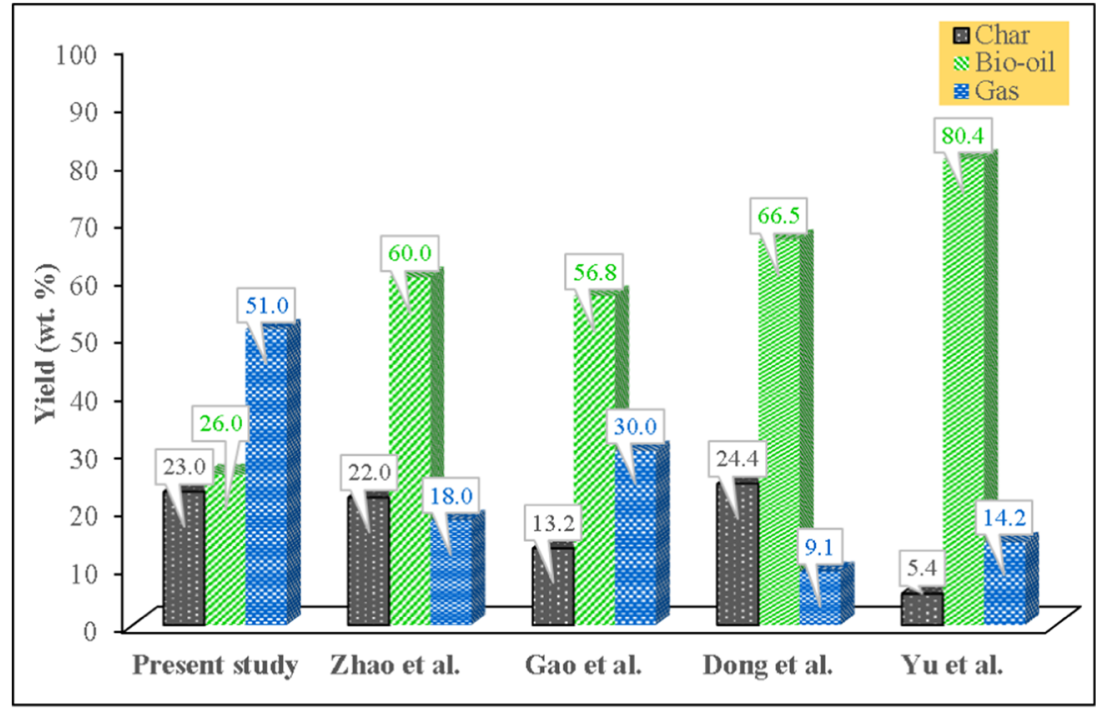

The tools were utilised to estimate the investment cost, operation cost, raw materials cost, product sales cost, utilities cost, equipment cost and equipment installation cost. The equations were used in this study to estimate the different costs and environmental emissions presented in our previous studies [34-36] and are summarised in Table 4. Aspen Plus reports the greenhouse gases (GHG) emissions in the form of carbon equivalents of global warming potential (GWP) with respect to data from three popular standards for reporting such emissions. The three standards include the IPCC 2nd Assessment Report on Climate Change from (1995), IPCC 4th Assessment Report on Climate Change from (2007) and the U.S. EPA's proposed rules from (2009). The emissions are calculated as a weighted sum of the mass flow rates of the GHG components using as weights the 100-year GWP as given by the specified standard. The net stream $\mathrm{CO}_{2}$ equivalents estimated using Eq. (9) are based on the IPCC 4th standard
[34-36]. The models of the three pseudo-biomass components, cellulose, hemicellulose and lignin, were compared and analysed to study their influence on the yield of char, syngas and bio-oil. The cost and emissions associated with the pyrolysis process were also assured using the model.

\section{Results and discussions}

\subsection{Model result and validation}

The developed model was validated using the input data reported in the work of Visconti and Miccio et al. and Table 5 presents the input data, the literature results and developed model. The obtained results were compared with the results of Visconti et al. [29]. It can be observed that the obtained results are in perfect agreement with the literature results of the Visconti et al [29].

Table 7 The reported proximate analysis results of cellulose, hemicellulose and lignin in earlier works [8, 40-42]

\begin{tabular}{|c|c|c|c|c|c|}
\hline \multirow[t]{2}{*}{ Biomass components } & \multirow[t]{2}{*}{ Earlier works } & \multicolumn{4}{|l|}{ Proximate analysis } \\
\hline & & Moisture (\% wt. basis) & Volatile matter (\% wt. basis) & Fixed carbon (\% wt. basis) & Ash (\% wt. basis) \\
\hline \multirow[t]{3}{*}{ Cellulose } & Zhao et al. [40] & 3.31 & 94.65 & 2.04 & 0.00 \\
\hline & Gao et al. [42] & 4.54 & 88.36 & 7.10 & 0.00 \\
\hline & Dong et al. [41] & $* \mathrm{NR}$ & 95.4 & $* \mathrm{NR}$ & $* \mathrm{NR}$ \\
\hline Hemicellulose & Zhao et al. [40] & 3.96 & 79.42 & 11.03 & 5.59 \\
\hline \multirow[t]{3}{*}{ Lignin } & Zhao et al. [40] & 3.42 & 67.23 & 25.50 & 3.85 \\
\hline & Shafaghat et al. [8] & 1.80 & 62.90 & 32.60 & 2.70 \\
\hline & Dong et al. [41] & $* \mathrm{NR}$ & $* \mathrm{NR}$ & 65.05 & $* \mathrm{NR}$ \\
\hline
\end{tabular}

$* N R$, not reported 
Fig. 3 Effect of hemicellulose on the slow pyrolysis products yield

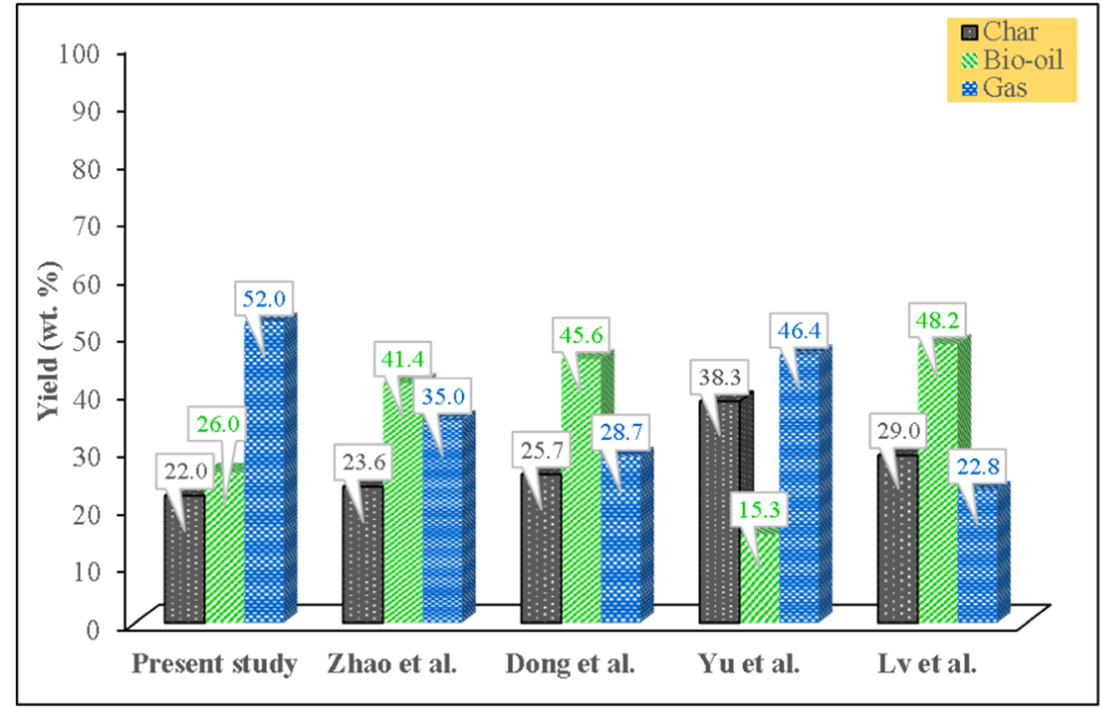

The pyrolysis of biomass involves the thermal conversion of the three pseudo-biomass components: lignin, cellulose and hemicellulose into different products that include char, bio-oil and syngas. Studying the effect of each pseudo-biomass component on the product yields would provide a better understanding of the economics of the process. The results of the pyrolysis simulation models are presented in Table 6. From Table 6, it can be observed that a char yield of $58 \%$ is obtained from lignin which was 2.4 and 2.5 times higher than cellulose and hemicellulose respectively. On the other hand, the cellulose and hemicellulose showed a higher yield of bio-oil about $26 \%$, which was about 8.67 times more than lignin. The syngas yield was higher for hemicellulose and cellulose about $52 \%$ and $51 \%$ respectively, compared to the lignin yield of $39 \%$. It can be noted that the pyrolysis of lignin favoured more char yield while cellulose and hemicellulose favoured more biooil and syngas yields.

\subsection{Effect of cellulose, hemicellulose, and lignin on slow pyrolysis products}

\subsubsection{Effect of cellulose on the slow pyrolysis products yield}

The effect of cellulose on the yield of char, bio-oil and gas in slow pyrolysis is presented in Fig. 2. Figure 2 also compares the slow pyrolysis product yields of the current work with other works of Zhao et al. [40], Dong et al. [41], Gao et al. [42] and $\mathrm{Yu}$ et al. [43].
Fig. 4 Effect of lignin on the slow pyrolysis products yield

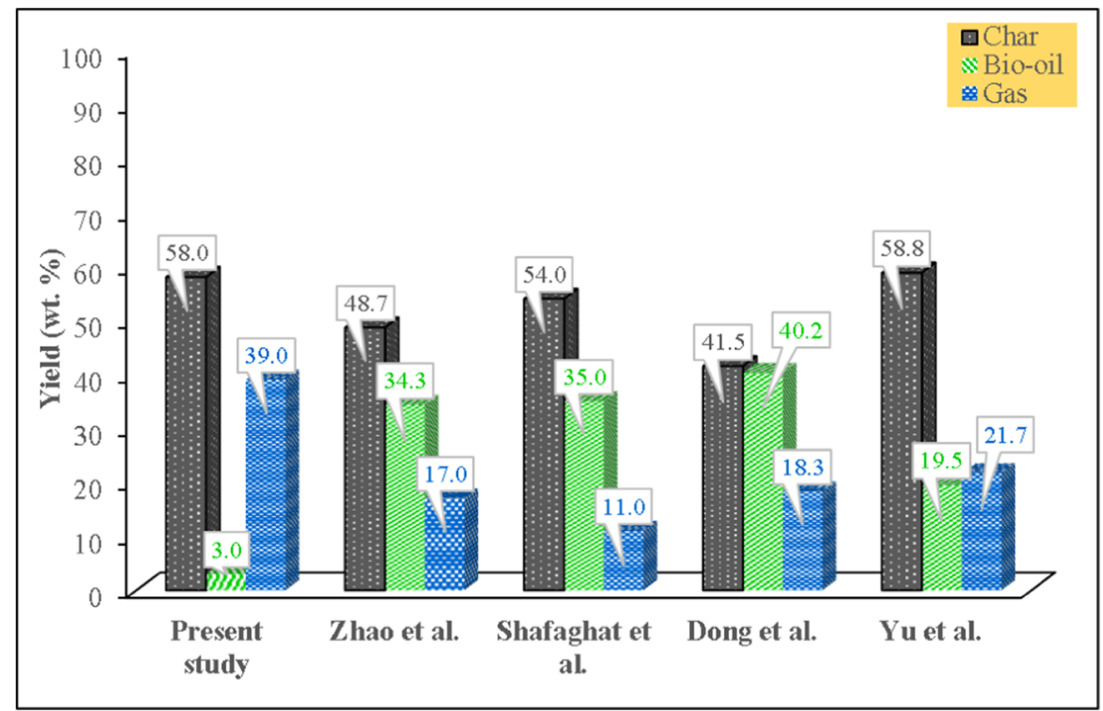


In the current work, it can be seen from Fig. 2 that the cellulose delivered significantly more gas yield than char and bio-oil yields. Also, it can be observed that the cellulose produced more bio-oil than char. In the other works (presented in Fig. 2), the cellulose favoured higher bio-oil yield than char and gas yields. However, next to the bio-oil yield, the cellulose did not offer a consistent yield of char and gas. Zhao et al. [40] and Dong et al. [41] observed cellulose favouring the char yield while Gao et al. [42] and $\mathrm{Yu}$ et al. [43] reported cellulose favouring the gas yield.

It can be inferred from Fig. 2 that at the given temperature, the cellulose will either favour a bio-oil or gas yield but not a char yield. In general, cellulose does not undergo thermal degradation readily owing to its crystalline structure [44]. However, when it degrades, it undergoes decomposition at a higher rate and the decomposition rate continues until it gets completely degraded $\left(400^{\circ} \mathrm{C}\right)$. This could be the reason for its high bio-oil and gas yield and poor char yield. The reported high yield of bio-oil in the works of Zhao et al. [40], Gao et al. [42], Dong et al. [41] and Yu et al. [43] could be due to the high volatile content of cellulose (see Table 7) [45]. As observed in the current study, cellulose could also favour the gas yield. Cellulose as such is porous in nature and this porous nature of cellulose allows the vapours formed during pyrolysis to react with solid particles favouring secondary reactions that could lead to more gas generation [46]. The difference in the product yield of cellulose in the above works could be due to the difference in the inherent nature and chemical properties of the cellulose that was used in the respective works.

\subsubsection{Effect of hemicellulose on the slow pyrolysis products yield}

The effect of hemicellulose on the slow pyrolysis products yield is presented in Fig. 3. In Fig. 3, the slow pyrolysis products yields of the current work are also compared with other works of Lv et al. [47], Yu et al. [43], Zhao et al. [40] and Dong et al. [41].

In the current work, it can be noticed from Fig. 3 that the hemicellulose delivered more gas yield than the bio-oil and char yield. Next to gas yield, the hemicellulose delivered more bio-oil yield. Also, it can be observed that the slow pyrolysis
Table 8 Results of the economic and environmental assessment of the model

\begin{tabular}{|c|c|c|c|}
\hline & Cellulose & Hemicellulose & Lignin \\
\hline \multicolumn{4}{|l|}{ Economics } \\
\hline Total capital cost $(\$)$ & $9.02 \mathrm{E}+06$ & $9.01 \mathrm{E}+06$ & $6.96 \mathrm{E}+06$ \\
\hline Total operating cost (\$/year) & $3.05 \mathrm{E}+06$ & $3.03 \mathrm{E}+06$ & $2.03 \mathrm{E}+06$ \\
\hline Raw material cost (\$/Ton) & $60[53]$ & $60[54]$ & $60[52]$ \\
\hline Total raw materials cost (\$/year) & $5.26 \mathrm{E}+07$ & $5.26 \mathrm{E}+07$ & $5.26 \mathrm{E}+07$ \\
\hline Total product sales (\$/year) & $7.71 \mathrm{E}+07$ & $7.51 \mathrm{E}+07$ & $1.06 \mathrm{E}+08$ \\
\hline Total utilities cost (\$/year) [35] & $1.28 \mathrm{E}+06$ & $1.26 \mathrm{E}+06$ & $3.65 \mathrm{E}+05$ \\
\hline Equipment cost $(\$)$ & $1.87 \mathrm{E}+06$ & $1.85 \mathrm{E}+06$ & $1.08 \mathrm{E}+06$ \\
\hline Total installed cost $(\$)$ & $3.89 \mathrm{E}+06$ & $3.88 \mathrm{E}+06$ & $2.60 \mathrm{E}+06$ \\
\hline Plant life (year) & 20 & & \\
\hline Rate of return $(\%)$ & 20 & & \\
\hline Total annualised (\$/year) & $5.75 \mathrm{E}+07$ & $5.74 \mathrm{E}+07$ & $5.60 \mathrm{E}+07$ \\
\hline \multicolumn{4}{|l|}{ Product sales (\$/year) } \\
\hline Bio-oil & $3.68 \mathrm{E}+07$ & $3.63 \mathrm{E}+07$ & $4.43 \mathrm{E}+06$ \\
\hline Syngas (dry) & $1.04 \mathrm{E}+05$ & $1.04 \mathrm{E}+05$ & $8.26 \mathrm{E}+04$ \\
\hline Char & $4.02 \mathrm{E}+07$ & $3.87 \mathrm{E}+07$ & $1.01 \mathrm{E}+08$ \\
\hline Cost per char product ( $\$ /$ Ton) & 285.73 & 296.55 & 110.41 \\
\hline Revenue per char product (\$/Ton) & 383.30 & 387.82 & 208.89 \\
\hline Net profit per char product (\$/Ton) & 97.57 & 91.27 & 98.49 \\
\hline Cost per bio-oil product (\$/Ton) & 250.61 & 253.84 & 2029.00 \\
\hline Revenue per bio-oil product (\$/Ton) & 336.19 & 331.97 & 3838.92 \\
\hline Net profit per bio-oil product ( $\$ /$ Ton) & 85.58 & 78.12 & 1809.93 \\
\hline Cost per syngas product (\$/Ton) & 128.94 & 125.96 & 164.25 \\
\hline Revenue per syngas product (\$/Ton) & 172.97 & 164.73 & 310.76 \\
\hline Net profit per syngas product (\$/Ton) & 44.03 & 38.77 & 146.51 \\
\hline Net $\mathrm{CO}_{2}$ emissions $\left(\mathrm{kg} \mathrm{CO}_{2}-\mathrm{e} / \mathrm{h}\right)$ & $235,210.46$ & $223,945.48$ & $56,876.24$ \\
\hline
\end{tabular}


Fig. 5 Production cost and revenue for the three pseudobiomass components

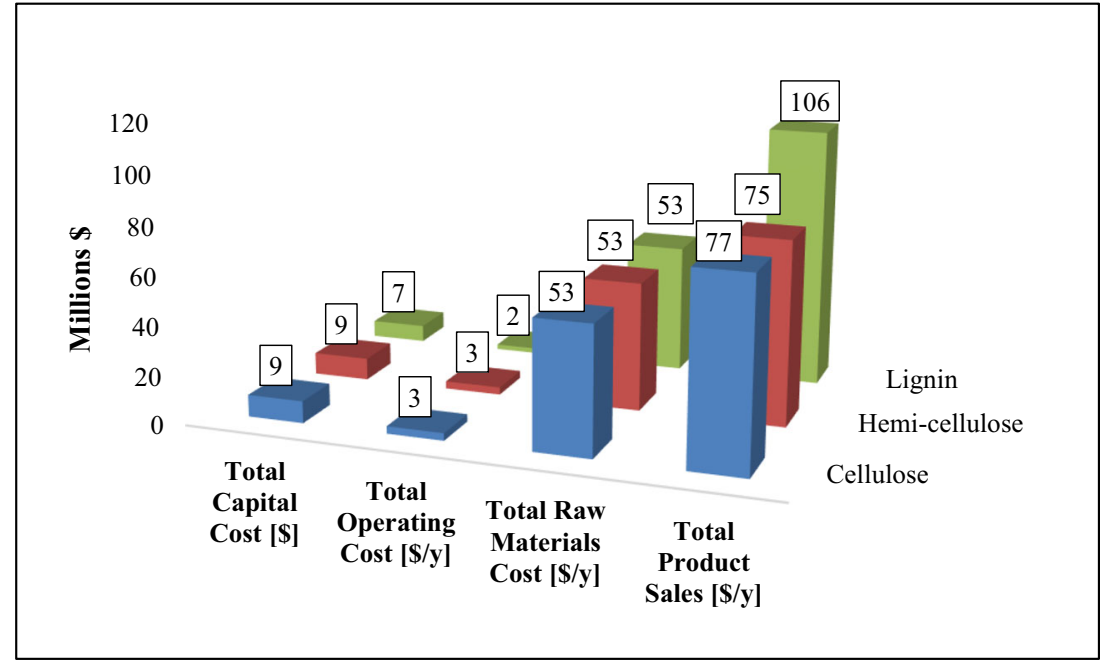

products yield of hemicellulose is similar to the slow pyrolysis products yield of cellulose. In the other works (presented in Fig. 3), the hemicellulose mostly favoured the bio-oil yield than char and gas yields. Next to bio-oil yield, the hemicellulose mostly supported the gas yield. It can be inferred that at $450{ }^{\circ} \mathrm{C}$, the hemicellulose will either favour the bio-oil or gas yield. This could be attributed to the thermal decomposition behaviour of hemicellulose [23]. As hemicellulose is mainly composed of amorphous structured saccharides, it readily undergoes degradation even at low temperatures. In fact, decomposes completely even before reaching $400{ }^{\circ} \mathrm{C}$. The high yield of bio-oil and gas could also be due to the high volatile content of hemicellulose [25] as can be seen in Table 7. Conversely, the low yield of char could be attributed to its low ash content as presented in Table 7 [48]. The discrepancy in the product yield of hemicellulose in the above works could be due to the difference in the physical and chemical characteristics of hemicellulose.

\subsubsection{Effect of lignin on the slow pyrolysis products yield}

The influence of lignin on the yield of char, bio-oil and gas in slow pyrolysis is presented in Fig. 4. Figure 4 also compares the slow pyrolysis products yields of the current work with other works of Shafaghat et al. [8], Yu et al. [43], Zhao et al. [40] and Dong et al. [41].

Table 9 Comparison of product costs with literature

\begin{tabular}{|c|c|c|c|c|}
\hline \multirow[t]{2}{*}{ Product } & \multicolumn{4}{|l|}{ Cost } \\
\hline & Cellulose & Hemicellulose & Lignin & Literature \\
\hline Char $(\$ / k g)$ & 0.29 & 0.30 & 0.11 & 0.2 [39] \\
\hline Bio-oil (\$/L) & 0.25 & 0.25 & 2.02 & $0.16[38]$ \\
\hline Syngas $\left(\$ / \mathrm{m}^{3}\right)$ & 0.31 & 0.32 & 0.29 & $0.11[37]$ \\
\hline
\end{tabular}

In the present work, lignin yielded more char $58 \%$ than biooil and gas yield. Second to the char yield, the lignin delivered more gas than bio-oil. In the other works (presented in Fig. 4), the lignin also favoured the highest char yield over bio-oil and gas yields. However, for the second highest yield after char, the lignin did not offer a consistent trend in the yields of biooil and gas. In the works of Zhao et al. [40], Shafaghat et al. [8] and Dong et al. [41], a relatively a higher yield of bio-oil was reported while in the work of Yu et al. [43], a higher yield of gas was observed. The high char yield of lignin could be attributed to the incomplete decomposition of lignin, since lignin is constituted of complex molecules, which undergo degradation at a wider temperature range, i.e. $160-900{ }^{\circ} \mathrm{C}$. At the given temperature of $450{ }^{\circ} \mathrm{C}$, lignin could not have undergone complete decomposition; hence, a high char yield is obtained [49]. The high fixed carbon of lignin could also have been contributed to the high char yield as presented in Table 7 [50]. Also, the presence of ash could have promoted the char yield as the inorganic elements in the ash acts as catalysts leading to more char formation as represented in Table 7 [51]. The variation in the product yields of lignin in the above works could be because of the difference in their physical and chemical properties.

\subsection{Techno-economic and environment evaluation}

The evaluation of the specific economic profitability for the three pseudo-biomass components is essential to study the influence on the overall viability of the pyrolysis process. In addition, coupling the economic evaluation with environmental impact assessment strengthens the comparison study and enhances the dual objective assessment. The results of the economic and environmental evaluation of the model are presented in Table 8 . The four main economic indicators namely product sales and the costs of capital, operating and raw materials are presented in Fig. 5 and it can be seen that raw 


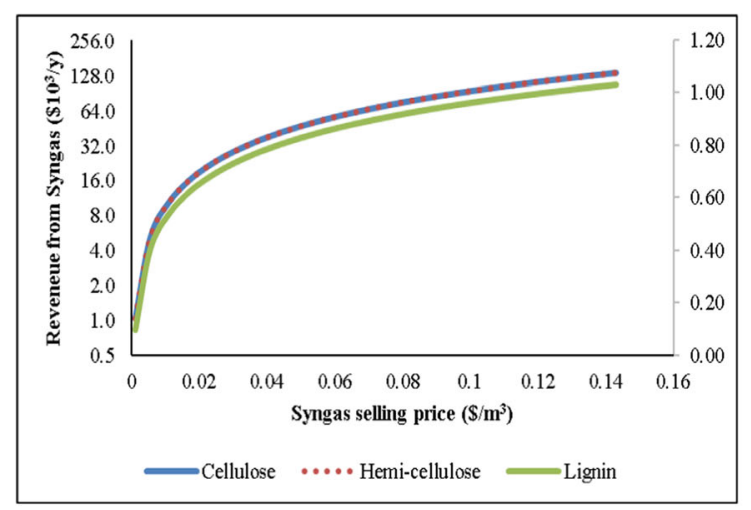

(a)

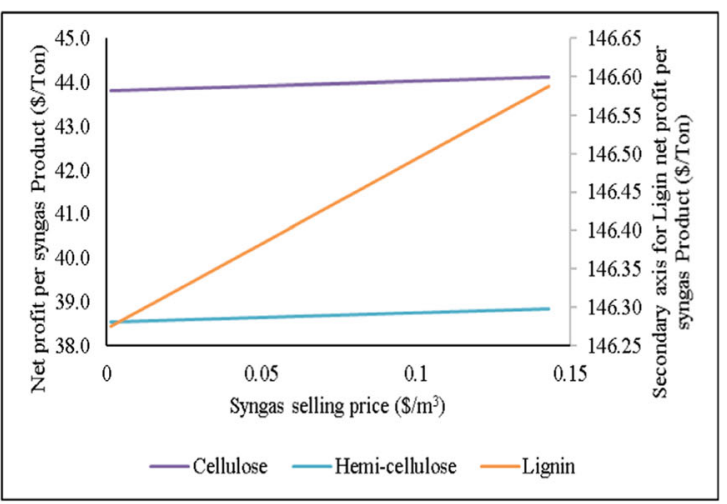

(b)

Fig. 6 Sensitivity trend of syngas. a Revenue and $\mathbf{b}$ net profit per syngas product against changes in the selling price

materials cost is the largest contributor to the overall cost. This high cost is originated from the high feedstock cost reported in literature [52]. By comparing and analysing the annualised cost against the generation rates of the different products indicates that the hemicellulose-based pyrolysis gives the highest positive net profit per char product. In particular, the production costs for char are 110.4 \$, 285.7 \$ and 296.5 \$ per ton using lignin, cellulose and hemicellulose respectively. Whereas, the revenues from char production demonstrate positive net profit for all pyrolysis cases with approximately 98.49, 91.27 and 97.57 \$ per ton of char produced using lignin, cellulose and hemicellulose respectively. The net profit from the production of bio-oil and syngas has also supported the economic feasibility of the pyrolysis process. The net $\mathrm{CO}_{2}$ emissions expressed as kilogram of $\mathrm{CO}_{2}$-e per hour indicate that lignin-based pyrolysis emits the lowest quantity of $\mathrm{CO}_{2}$ environmental emissions.

The results of product costs demonstrate good agreement with literature values as illustrated in Table 9. The reported product cost for biochar in literature ranged between $\$ 0.2$ and $0.8 / \mathrm{kg}$ which demonstrates good agreement with the current study value estimated in the range of $\$ 0.1-0.3 / \mathrm{kg}$. In addition, the product costs of bio-oil and syngas from the current study

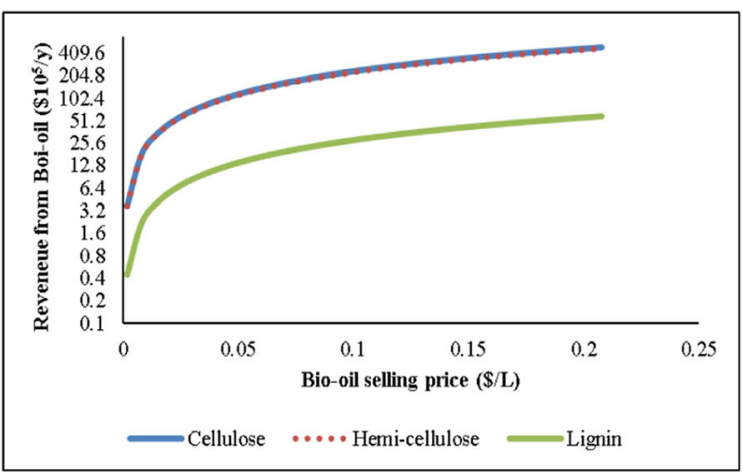

(a) estimated at $\$ 0.3 / \mathrm{m}^{3}$ and $\$ 0.25 / \mathrm{L}$ are in the range of reported literature values. The case for Lignin pyrolysis has reported some deviation from the reported literature values which can be due to the high char yield compared to the other two studies.

In an effort to assess the potential variation in the prices of the different products generated from the slow pyrolysis process, this study further evaluates the effect on the revenue and net profit. The prices of the products are varied from $1 \%$ of the original price to $30 \%$ above the original price. Figures 6,7 and 8 illustrate the trends of resulted revenue and net profit for the different biomass components as a function of the product's prices. The sensitivity trends of the revenue and net profit from the different products demonstrate strong behaviour for syngas results compared to char and bio-oil. Decreasing the price to $1 \%$ of the original reported literature value for the three products show no negative results for the net profit per syngas product while the trends for bio-oil and char products indicate a breakpoint in the net profit approximately at 0.88 $\$ / \mathrm{L}$ and $0.11 \$ / \mathrm{kg}$, respectively. Among the different components, lignin was found the most to resist the change in the selling price of the different products. The revenue from the different products demonstrates sharp increase at small selling

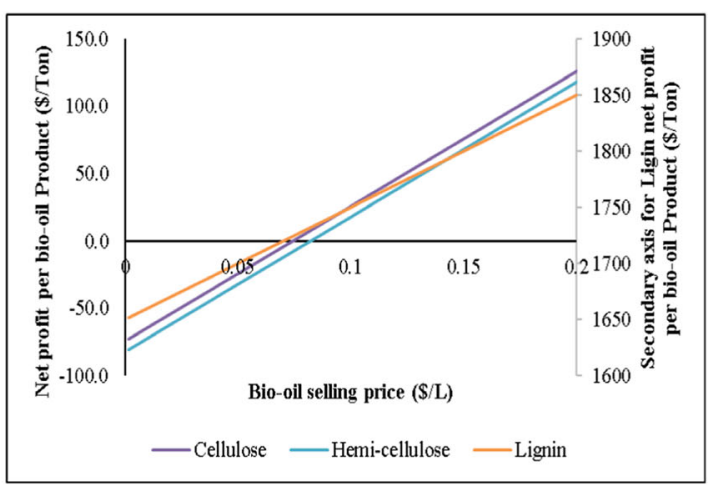

(b)

Fig. 7 Sensitivity trend of bio-oil. a Revenue and $\mathbf{b}$ net profit per bio-oil product against changes in the selling price 


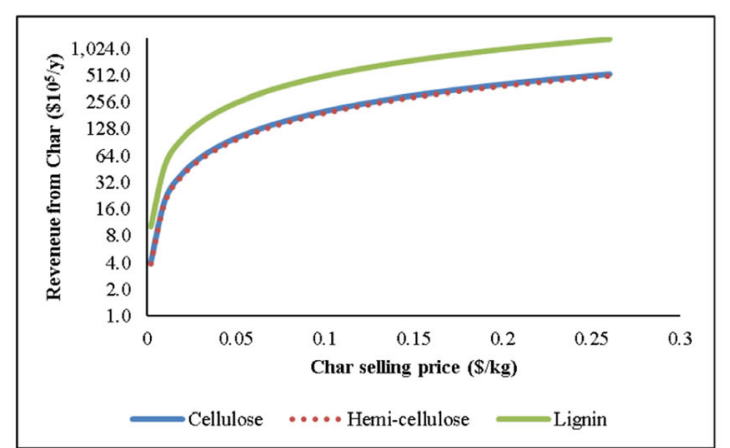

(a)

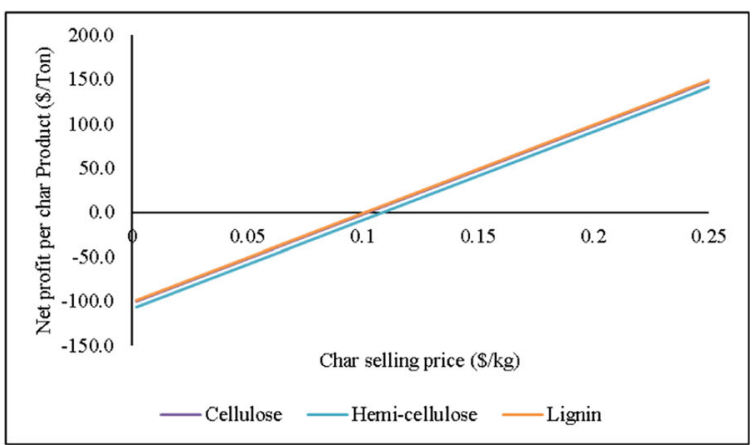

(b)

Fig. 8 Sensitivity trend of char. a Revenue and $\mathbf{b}$ net profit per char product against changes in the selling price

prices between $\$ 0-0.02 / \mathrm{m}^{3}, \$ 0-0.05 / \mathrm{L}$ and $\$ 0-0.05 / \mathrm{kg}$ for syngas, bio-oil and char, respectively. Whereas, increasing the selling prices prove to flatten the revenue trend. Similar to the previous observations, the revenues from syngas and bio-oil are more for cellulose and hemi-cellulose, while the revenue from char is more for lignin.

\section{Conclusion}

This study investigated the effect of biomass components (cellulose, hemicellulose and lignin) on pyrolysis product yields such as bio-oil, char and syngas using an ASPEN Plus-based model. The simulation study was performed at a pyrolysis temperature of $450{ }^{\circ} \mathrm{C}$, a heating rate of $10^{\circ} \mathrm{C} / \mathrm{min}$ and a solid residence time of $30 \mathrm{~min}$. The simulation results indicated that at the given conditions, the lignin contributed 2.4 and 2.5 times more char yield than cellulose and hemicellulose respectively. The hemicellulose, on the other hand, contributed 1.33 times more syngas yield than lignin while the cellulose and hemicellulose contributed 8.67 times more bio-oil yield than lignin. It can be inferred that lignin favours char yield while cellulose and hemicellulose favour bio-oil yield. The technoeconomic analysis indicated that the cost involved in the production of char using lignin (110 \$/ton) was significantly lower than using cellulose ( 285 \$/ton) and hemicellulose (296 $\$ /$ ton). The net $\mathrm{CO}_{2}$ emission of lignin pyrolysis was 4.14 times lower than cellulose pyrolysis and 4.15 times lower than hemicellulose pyrolysis. It can be concluded that lignin pyrolysis is more advantageous than cellulose and hemicellulose pyrolysis. In the selection of feedstock for the slow pyrolysis, feedstock with more lignin should be always preferred. The present study is based on the assumption that there is no interaction between individual components during pyrolysis. However, in a real case, there will definitely be some interactions between the components of biomass. Hence, future studies should develop a model considering individual as well as synergistic effects of the biomass components.
Acknowledgements The authors are grateful to Hamad Bin Khalifa University (HBKU) and Qatar Foundation (QF) for their financial support. In addition, this study was supported by the Qatar National Research Fund, Grant number NPRP11S-0117-180328.

Funding Open Access funding provided by the Qatar National Library.

\section{Compliance with ethical standards}

Conflict of interest The authors declare that they have no conflict of interest.

Open Access This article is licensed under a Creative Commons Attribution 4.0 International License, which permits use, sharing, adaptation, distribution and reproduction in any medium or format, as long as you give appropriate credit to the original author(s) and the source, provide a link to the Creative Commons licence, and indicate if changes were made. The images or other third party material in this article are included in the article's Creative Commons licence, unless indicated otherwise in a credit line to the material. If material is not included in the article's Creative Commons licence and your intended use is not permitted by statutory regulation or exceeds the permitted use, you will need to obtain permission directly from the copyright holder. To view a copy of this licence, visit http://creativecommons.org/licenses/by/4.0/.

\section{References}

1. Shrivastava P, Khongphakdi P, Palamanit A, Kumar A, Tekasakul P (2020) Investigation of physicochemical properties of oil palm biomass for evaluating potential of biofuels production via pyrolysis processes. Biomass Convers Biorefin. https://doi.org/10.1007/ s13399-019-00596-x

2. Heracleous E, Lappas A, Serrano D (2017) Special thematic issue in "Biomass Conversion and Biorefinery" "Advances in catalytic biomass fast pyrolysis and bio-oil upgrading." Biomass Convers Biorefin 7(3):275-276. https://doi.org/10.1007/s13399-017-02844

3. Naqvi SR, Ali I, Nasir S, Ali Ammar Taqvi S, Atabani AE, Chen W-H (2020) Assessment of agro-industrial residues for bioenergy potential by investigating thermo-kinetic behavior in a slow pyrolysis process. Fuel 278:118259. https://doi.org/10.1016/j.fuel.2020. 118259

4. Ghiat I, AlNouss A, McKay G, Al-Ansari T (2020) Biomass-based integrated gasification combined cycle with post-combustion $\mathrm{Co} 2$ 
recovery by potassium carbonate: techno-economic and environmental analysis. Comput Chem Eng:106758. https://doi.org/10. 1016/j.compchemeng.2020.106758

5. Ghysels S, Ronsse F, Dickinson D, Prins W (2019) Production and characterization of slow pyrolysis biochar from lignin-rich digested stillage from lignocellulosic ethanol production. Biomass Bioenergy 122:349-360. https://doi.org/10.1016/j.biombioe.2019. 01.040

6. Jae J, Tompsett GA, Lin Y-C, Carlson TR, Shen J, Zhang T, Yang B, Wyman CE, Conner WC, Huber GW (2010) Depolymerization of lignocellulosic biomass to fuel precursors: maximizing carbon efficiency by combining hydrolysis with pyrolysis. Energy Environ Sci 3(3):358-365. https://doi.org/10.1039/B924621P

7. Pandey A, Negi S, Binod P, Larroche C (2014) Pretreatment of biomass: processes and technologies. Academic Press, Cambridge

8. Shafaghat H, Rezaei PS, Ro D, Jae J, Kim B-S, Jung S-C, Sung BH, Park Y-K (2017) In-situ catalytic pyrolysis of lignin in a benchscale fixed bed pyrolyzer. J Ind Eng Chem 54:447-453

9. Vieira FR, Romero Luna CM, Arce GLAF, Ávila I (2020) Optimization of slow pyrolysis process parameters using a fixed bed reactor for biochar yield from rice husk. Biomass Bioenergy 132:105412. https://doi.org/10.1016/j.biombioe.2019.105412

10. Inayat M, Sulaiman SA, Shahbaz M, Bhayo BA (2020) Application of response surface methodology in catalytic co-gasification of palm wastes for bioenergy conversion using mineral catalysts. Biomass Bioenergy 132:105418

11. Özsin G, Pütün AE, Pütün E (2019) Investigating the interactions between lignocellulosic biomass and synthetic polymers during copyrolysis by simultaneous thermal and spectroscopic methods. Biomass Convers Biorefin 9(3):593-608. https://doi.org/10.1007/ s13399-019-00390-9

12. Shahbaz M, Al-Ansari $T$, Aslam $M$, Khan Z, Inayat A, Athar M, Naqvi SR, Ahmed MA, McKay G (2020) A state of the art review on biomass processing and conversion technologies to produce hydrogen and its recovery via membrane separation. Int J Hydrog Energy 45(30):15166-15195. https://doi.org/10.1016/j.ijhydene. 2020.04.009

13. López-Renau LM, García-Pina L, Hernando H, Gómez-Pozuelo G, Botas JA, Serrano DP (2019) Enhanced bio-oil upgrading in biomass catalytic pyrolysis using KH-ZSM-5 zeolite with acid-base properties. Biomass Convers Biorefin. https://doi.org/10.1007/ s13399-019-00455-9

14. Naqvi SR, Hameed Z, Tariq R, Taqvi SA, Ali I, Niazi MBK, Noor T, Hussain A, Iqbal N, Shahbaz M (2019) Synergistic effect on copyrolysis of rice husk and sewage sludge by thermal behavior, kinetics, thermodynamic parameters and artificial neural network. Waste Manag 85:131-140

15. Habibi Y, Lucia LA, Rojas OJ (2010) Cellulose nanocrystals: chemistry, self-assembly, and applications. Chem Rev 110(6): 3479-3500

16. Poletto M, Ornaghi H, Zattera A (2014) Native cellulose: structure, characterization and thermal properties. Materials 7(9):6105-6119

17. Lin H, Wang S, Zhang L, Ru B, Zhou J, Luo Z (2017) Structural evolution of chars from biomass components pyrolysis in a xenon lamp radiation reactor. Chin J Chem Eng 25(2):232-237

18. Ma Z, Yang Y, Wu Y, Xu J, Peng H, Liu X, Zhang W, Wang S (2019) In-depth comparison of the physicochemical characteristics of bio-char derived from biomass pseudo components: hemicellulose, cellulose, and lignin. J Anal Appl Pyrolysis 140:195-204

19. Yang H, Yan R, Chen H, Lee DH, Zheng C (2007) Characteristics of hemicellulose, cellulose and lignin pyrolysis. Fuel 86(12-13): 1781-1788

20. Wu W, Mei Y, Zhang L, Liu R, Cai J (2014) Effective activation energies of lignocellulosic biomass pyrolysis. Energy Fuel 28(6): 3916-3923. https://doi.org/10.1021/ef5005896
21. McKendry P (2002) Energy production from biomass (part 1): overview of biomass. Bioresour Technol 83(1):37-46

22. Chen L, Liao Y, Guo Z, Cao Y, Ma X (2019) Products distribution and generation pathway of cellulose pyrolysis. J Clean Prod 232: 1309-1320. https://doi.org/10.1016/j.jclepro.2019.06.026

23. Stefanidis SD, Kalogiannis KG, Iliopoulou EF, Michailof CM, Pilavachi PA, Lappas AA (2014) A study of lignocellulosic biomass pyrolysis via the pyrolysis of cellulose, hemicellulose and lignin. J Anal Appl Pyrolysis 105:143-150. https://doi.org/10. 1016/j.jaap.2013.10.013

24. Mettler MS, Vlachos DG, Dauenhauer PJ (2012) Top ten fundamental challenges of biomass pyrolysis for biofuels. Energy Environ Sci 5(7):7797-7809. https://doi.org/10.1039/ C2EE21679E

25. Jahirul M, Rasul M, Chowdhury A, Ashwath N (2012) Biofuels production through biomass pyrolysis - a technological review. Energies 5(12):4952-5001

26. Kabir M, Chowdhury A, Rasul M (2015) Pyrolysis of municipal green waste: a modelling, simulation and experimental analysis. Energies 8(8):7522-7541

27. Peters JF, Banks SW, Bridgwater AV, Dufour J (2017) A kinetic reaction model for biomass pyrolysis processes in Aspen Plus. Appl Energy 188:595-603

28. Peters J, Iribarren D, Dufour J (2014) Predictive pyrolysis process modelling in Aspen Plus

29. Visconti A, Miccio M, Juchelková D (2015) An aspen plus tool for simulation of lignocellulosic biomass pyrolysis via equilibrium and ranking of the main process variables. Int J Math Models Meth Appl Sci 9:71-86

30. Xianjun X, Zongkang S, Peiyong M, Jin Y, Zhaobin W (2015) Establishment of three components of biomass pyrolysis yield model. Energy Procedia 66:293-296. https://doi.org/10.1016/j.egypro. 2015.02.061

31. Peters JF, Iribarren D, Dufour J (2015) Biomass pyrolysis for biochar or energy applications? A life cycle assessment. Environ Sci Technol 49(8):5195-5202. https://doi.org/10.1021/es5060786

32. AlNouss A, McKay G, Al-Ansari T (2020) Production of syngas via gasification using optimum blends of biomass. J Clean Prod 242:118499. https://doi.org/10.1016/j.jclepro.2019.118499

33. AlNouss A, McKay G, Al-Ansari T (2018) Optimum utilization of biomass for the production of power and fuels using gasification. In: Computer aided chemical engineering, vol 43. Elsevier, Amsterdam, pp 1481-1486

34. AlNouss A, McKay G, Al-Ansari T (2019) A techno-economicenvironmental study evaluating the potential of oxygen-steam biomass gasification for the generation of value-added products. Energy Convers Manag 196:664-676. https://doi.org/10.1016/j. enconman.2019.06.019

35. AlNouss A, McKay G, Al-Ansari T (2019) Superstructure optimization for the production of fuels, fertilizers and power using biomass gasification. In: Kiss AA, Zondervan E, Lakerveld R, Özkan L (eds) Computer aided chemical engineering, vol 46. Elsevier, Amsterdam, pp 301-306. https://doi.org/10.1016/B978-0-12818634-3.50051-5

36. AlNouss A, Namany S, McKay G, Al-Ansari T (2019) Applying a sustainability metric in energy, water and food Nexus applications; a biomass utilization case study to improve investment decisions. In: Kiss AA, Zondervan E, Lakerveld R, Özkan L (eds) Computer aided chemical engineering, vol 46. Elsevier, Amsterdam, pp 205210. https://doi.org/10.1016/B978-0-12-818634-3.50035-7

37. Industry L (2015) SinoCoking reports sales of US $\$ 5$ million. Palladian Publications Ltd., Farnham

38. Stewart GW (2004) Bio-oil commercialization plan. Cole Hill Associates, Wimborne

39. Ashraf MT, Lopez CG-B, Yousef L, Schmidt JE Economic analysis of biochar production from date palm fronds 
40. Zhao C, Jiang E, Chen A (2017) Volatile production from pyrolysis of cellulose, hemicellulose and lignin. J Energy Inst 90(6):902-913

41. Dong Z, Liu Z, Zhang X, Yang H, Li J, Xia S, Chen Y, Chen H (2019) Pyrolytic characteristics of hemicellulose, cellulose and lignin under $\mathrm{CO}_{2}$ atmosphere. Fuel 256:115890

42. Gao Z, Li N, Yin S, Yi W (2019) Pyrolysis behavior of cellulose in a fixed bed reactor: residue evolution and effects of parameters on products distribution and bio-oil composition. Energy 175:10671074

43. Yu J, Paterson N, Blamey J, Millan M (2017) Cellulose, xylan and lignin interactions during pyrolysis of lignocellulosic biomass. Fuel 191:140-149

44. Quan C, Gao N, Song Q (2016) Pyrolysis of biomass components in a TGA and a fixed-bed reactor: thermochemical behaviors, kinetics, and product characterization. J Anal Appl Pyrolysis 121:84 92

45. Chouhan APS, Sarma AK (2013) Critical analysis of process parameters for bio-oil production via pyrolysis of biomass: a review. Recent Pat Eng 7:1-17

46. Giudicianni P, Cardone G, Ragucci R (2013) Cellulose, hemicellulose and lignin slow steam pyrolysis: thermal decomposition of biomass components mixtures. J Anal Appl Pyrolysis 100:213222. https://doi.org/10.1016/j.jaap.2012.12.026
47. Lv G-J, Wu S-B, Lou R (2010) Characteristics of corn stalk hemicellulose pyrolysis in a tubular reactor. BioResources 5(4):20512062

48. Trubetskaya A, Jensen PA, Jensen AD, Steibel M, Spliethoff H, Glarborg P (2015) Influence of fast pyrolysis conditions on yield and structural transformation of biomass chars. Fuel Process Technol 140:205-214

49. Dalluge DL, Kim KH, Brown RC (2017) The influence of alkali and alkaline earth metals on char and volatile aromatics from fast pyrolysis of lignin. J Anal Appl Pyrolysis 127:385-393

50. Werner K, Pommer L, Broström M (2014) Thermal decomposition of hemicelluloses. J Anal Appl Pyrolysis 110:130-137

51. Maddi B, Viamajala S, Varanasi S (2011) Comparative study of pyrolysis of algal biomass from natural lake blooms with lignocellulosic biomass. Bioresour Technol 102(23):11018-11026

52. Hodásová L', Jablonsky M, Andrea S, Haz A (2015) Lignin, potential products and their market value. Wood Res 60(6):973-986

53. Tsao GT (2014) Annual reports on fermentation processes. Elsevier, Amsterdam

54. Karkee A (2016) Optimization and cost analysis of lignocellulosic biomass feedstocks supply chains for biorefineries

Publisher's Note Springer Nature remains neutral with regard to jurisdictional claims in published maps and institutional affiliations. 